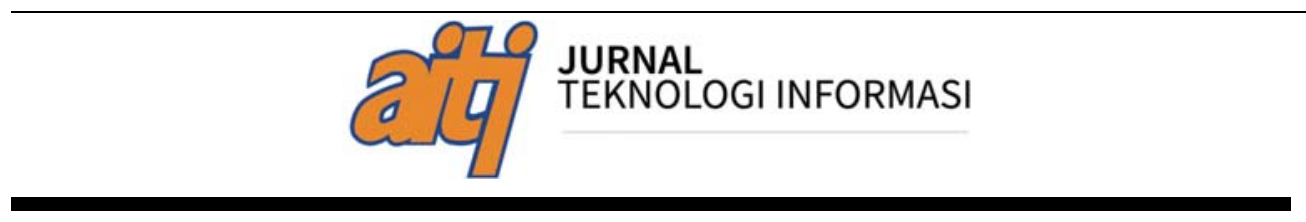

\title{
Implementasi Pemetaan Perilaku Hidup Bersih Sehat Menggunakan Framework CodeIgniter dan Google Maps API (Studi Kasus Dinas Kesehatan Kota Salatiga)
}

\author{
Ade Kresna Dewantara, Evang Mailoa \\ Program Studi Teknik Informatika, Fakultas Teknologi Informasi \\ Universitas Kristen Satya Wacana \\ J1. Diponegoro 52-60, Salatiga 50711, Indonesia \\ Email : evang.mailoa@uksw.edu
}

\begin{abstract}
Health Department of Salatiga is one of public Health Department which is give service and information about health in Salatiga. One that is less published information from Health Department of Salatiga is healthy hygienic behavior. This information important to be known by the public so that public can active in overcome about health issues. Absence of media and methods of data collection which is not relevant make this information not published by Health Department of Salatiga. This research apply the codeigniter technology and google maps api to build the geographic information system. The purpose of using this technology because codeigniter technology has been provide lots of divining manual to accelerate making an application. The technology API and Google Maps can be used to mapping PHBS level in small region at Salatiga city. Mapping result can used by public to obtain information about PHBS level in Salatiga city, so it can be used as reference for improving PHBS level by increasing health hygienic behavior.
\end{abstract}

Keywords: Mapping, Health Department, CodeIgniter

\begin{abstract}
Abstrak
Dinas Kesehatan Kota Salatiga merupakan salah satu dinas pelayanan publik yang memberikan layanan serta informasi kesehatan di wilayah Kota Salatiga. Salah satu informasi kesehatan yang kurang dipublikasikan oleh Dinas Kesehatan Kota Salatiga adalah Perilaku Hidup Bersih Sehat tatanan Rumah Tangga (PHBS). Informasi ini penting diketahui publik agar masyarakat turut berperan aktif dalam menanggulangi masalah kesehatan di tatanan rumah tangga. Tidak adanya media serta metode pengambilan data yang tidak relevan menyebabkan informasi PHBS tidak terpublikasi. Penelitan ini menerapkan framework Codeigniter serta Google Maps API untuk membangun pemetaan PHBS. Tujuan penggunaannya karena codeigniter telah menyediakan banyak pustaka yang bisa digunakan untuk mempercepat pembuatan suatu aplikasi. Adanya teknologi API dan Google Maps digunakan untuk memetakan strata PHBS tingkat kelurahan di Kota Salatiga. Hasil pemetaan dapat digunakan oleh masyarakat untuk mendapatkan informasi mengenai strata PHBS di Kota Salatiga yang nantinya dapat dijadikan sebagai acuan untuk mengatasi permasalahan kesehatan di lingkungannya secara mandiri.
\end{abstract}

Kata kunci: Pemetaan, Dinas Kesehatan, Codeigniter 


\section{Pendahuluan}

Perilaku Hidup Bersih Sehat (PHBS) merupakan salah satu program dari Dinas Kesehatan Kota Salatiga dalam mencapai visi "Masyarakat Kota Salatiga yang sehat, mandiri, dan berkeadilan.” PHBS bertujuan meningkatkan, memelihara, dan melindungi kesehatannya baik fisik, mental, spiritual maupun sosial [1]. Diharapkan dengan adanya PHBS, masyarakat Kota Salatiga dapat menolong dirinya sendiri di bidang kesehatan dan berperan aktif dalam mewujudkan masyarakat sehat.

PHBS Tatanan Rumah Tangga adalah upaya untuk memberdayakan anggota rumah tangga agar tahu,mau dan mampu melaksanakan perilaku hidup bersih dansehat serta berperan aktif dalam gerakan kesehatan masyarakat. PHBS di rumah tangga dilakukan untuk mencapai rumah tangga sehat. Rumah tangga sehat berarti mampu menjaga, meningkatkan dan melindungi kesehatan setiap anggota rumah tangga dari gangguan ancaman penyakit dan lingkungan kurang kondusif untuk hidup sehat [2]. Terdapat 16 indikator PHBS rumah tangga terlihat pada Gambar 1.

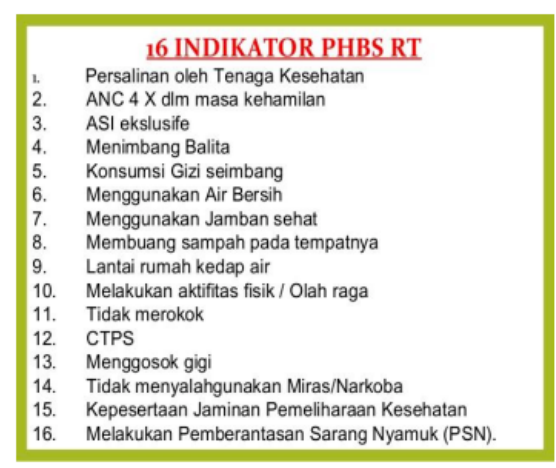

Gambar 1 Indikator PHBS [3]

Sejak 2011 hingga saat ini, Dinas Kesehatan Kota Salatiga menggunakan metode Rapid Survey untuk menetapkan strata PHBS tiap kelurahan [4]. Ditemukan kendala pada metode tersebut yaitu pada saat data diambil dan diolah yang mengakibatkan proses kerja kurang efisien dari segi waktu serta keakuratan data. Hasil dari survei tersebut masih bersifat manual dan jangka pendek. Metode tersebut dinilai masih kurang relevan dengan kondisi masyarakat Kota Salatiga yang tiap hari makin bertambah. Kendala lain yang ditemukan adalah masyarakat tidak dapat mengetahui strata PHBS di tingkat kelurahannya masing- masing dikarenakan belum ada media untuk informasi tersebut.

Kendala-kendala yang ditemukan menyebabkan terhambatnya kinerja dari Dinas Kesehatan untuk menentukan strata PHBS Rumah Tangga tiap kelurahan sehingga diperlukan suatu sistem yang multifungsi, yaitu dapat melakukan pengolahan data serta dapat menjadi sarana informasi bagi masyarakat Kota 
AITI: Jurnal Teknologi Informasi

Volume 16 No. 1 Februari 2019, 1-17

Salatiga. Sarana informasi yang dimaksud adalah masyarakat dapat mengetahui secara visual tingkat strata PHBS Rumah Tangga tiap kelurahan di Kota Salatiga.

Teknologi framework serta Google Maps API digunakan untuk memecahkan permasalahan baik pengolahan data maupun pemetaan. Website dipilih karena sifatnya yang mudah diakses oleh siapa saja dan dimana saja tanpa harus dibatasi perangkat. Diperlukannya juga media yang universal tanpa harus melakukan installing software yang dapat merepotkan user menjadi pertimbangan lain penggunaan website.

Diperlukannya Framework CodeIgniter dalam membangun sistem pemetaan karena proses maintenance yang mudah dilakukan ketika produk mengalami masalah. Konsep Model, View, Controller yang memisahkan tiap proses database maupun proses bisnis aplikasi memudahkan dalam membangun sebuah website. Google Maps API digunakan sebagai sumber peta karena pemetaan yang dibuat dapat menampilkan peta yang langsung terintegrasi dengan Google Maps sehingga keakuratan peta terjamin.

\section{Kajian Pustaka}

Pada penelitian "Sistem Informasi Geografis Dengan Fitur Peta dan Rute Perjalanan Studi Kasus Kabupaten Malang" menggunakan website geographic system untuk mempermudah wisatawan baik wisatawan lokal maupun mancanegara dalam mencari tempat-tempat wisata di kota Malang. Fitur dari website ini antara lain keterangan tempat wisata, rating, news, maps dan rute perjalanan. Rute dan peta telah disesuaikan dengan kondisi lokasi yang sebenarnya melalui proses survey serta peninjuan langsung ke lokasi wisata [5].

Penelitian lain berjudul "Sistem Informasi Geografis Pemetaan Potensi SMA/SMK Berbasis Web Studi Kasus Kabupaten Kebumen" menggunakan konsep website serupa untuk membantu siswa-siswi SMP di Kabupaten Kebumen dalam mencari informasi SMA-SMK se-kabupaten Kebumen. Fitur dari website ini antara lain layanan informasi tentang ekstrakurikuler, akreditasi, fasilitas pendukung sekolah, jumlah siswa dan tenaga pengajar [6].

Penelitian ini memiliki perbedaan dengan penelitian - penelitian sebelumnya yaitu penelitian ini merancang sistem pemetaan berbasis web dengan sumber peta berasal dari Goggle Maps dan pemrograman menggunakan library Google Maps API serta PHP berbasis framework CodeIgniter. Digunakannya fitur polygon untuk menunjukkan suatu area yang lebih luas dibanding fitur point marker yang telah digunakan oleh penelitian - penelitian sebelumnya. Fitur dari sistem ini menginformasikan strata wilayah PHBS per kelurahan, serta pengolahan data yang dinamis.

Sistem informasi geografis merupakan sebuah sistem yang terdiri dari software dan hardware, data dan pengguna serta institusi untuk menyimpan data 
yang berhubungan dengan semua fenomena yang ada di muka bumi. Data - data berupa detail fakta, kondisi dan informasi disimpan dalam suatu basis data dan akan digunakan untuk berbagai macam keperluan seperti analisis, manipulasi, penyajian dan sebagainya.[7]

Sistem Informasi Geografis juga merupakan penggabungan antara unsur peta dan informasi tentang peta tersebut yang dirancang untuk mendapatkan, mengolah, memanipulasi, analisis, memperagakan dan menampilkan data spasial untuk menyelesaikan perencanaan, mengolah, dan meneliti permasalahan. SIG pada dasarnya gabungan dari tiga unsur pokok, yaitu: sistem,informasi dan geografis. SIG menekankan pada informasi geografis. Istilah informasi geografis mengandung pengertian informasi mengenai tempat- tempat yang terletak di permukaan bumi, dan informasi mengenai dan informasi mengenai keterangan keterangan yang terdapat di permukaan bumi yang posisinya diberikan dan diketahui. SIG membantu manusia untuk memahami dunia nyata dengan melakukan proses - proses manipulasi dan presentasi data yang direalisasikan dengan lokasi - lokasi geografis permukaan bumi [8].

CodeIgniter merupakan framework aplikasi web terbuka yang digunakan untuk membangun aplikasi PHP dinamis. Tujuan utama framework ini agar pengembang bekerja secara cepat tanpa perlu menulis ulang kode. CodeIgniter diperkenalkan pada 28 Februari 2006. Karakteristik dari CodeIgniter sebagai berikut :

1. Fleksibel dan ringan sehingga mudah untuk belajar, memodifikasi dan mengintegrasikan Library dan Helper.

2. Menggunakan struktur MVC (Model, View, Controller) sehingga kode lebih terstruktur dan rapi

3. Memiliki URL yang mudah dimengerti. CodeIgniter mengurangi penggunaan \$_GET kemudian menggantinya dengan URL.

Gambar 2 menampilkan cara kerja framework CodeIgniter.

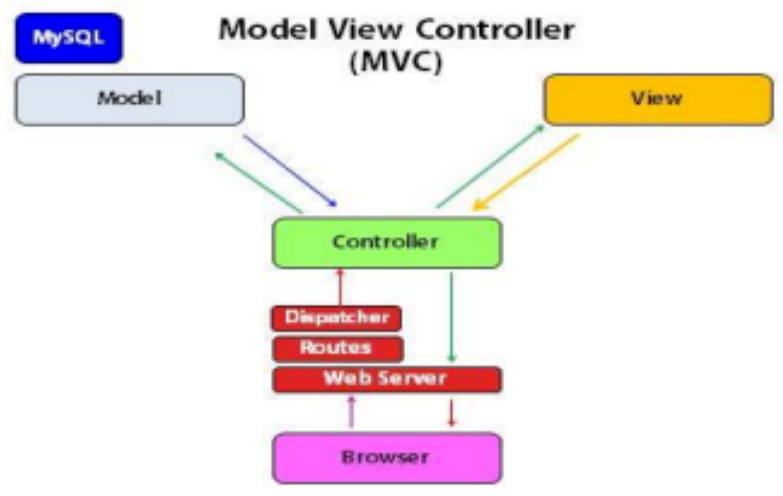

Gambar 2 Cara kerja CodeIgniter [9] 
AITI: Jurnal Teknologi Informasi

Secara umum, struktur CodeIgniter bekerja dimulai dari browser dimana browser akan saling berinteraksi melalui controller, kemudian controller menerima dan membalas semua request dari browser. Controller kemudian meminta request kepada model untuk mendapatkan data, sedangkan untuk user interface meminta request kepada view. Garis besarnya dapat disimpulkan ketika browser mengakses halaman web, route akan otomatis mencari controller yang bertugas menangani request, kemudian controller akan digunakan untuk mengakses data serta UI.

Struktur MVC pada CodeIgniter digunakan untuk memisahkan data access dan business-logic dari interaksi user. Pemisahan telah dilakukan sebelumnya sehingga setiap ada perubahan pada data access maupun business-logic tidak memberikan dampak yang kompleks pada sistem. Pemisahan MVC merupakan solusi yang diharapkan untuk meningkatkan fleksibilitas dan reuseability aplikasi.

Arsitektur MVC membagi aplikasi ke dalam 3 bentuk yang sering disebut model, view, controller. Arsitektur MVC dapat dilihat pada Gambar 3.

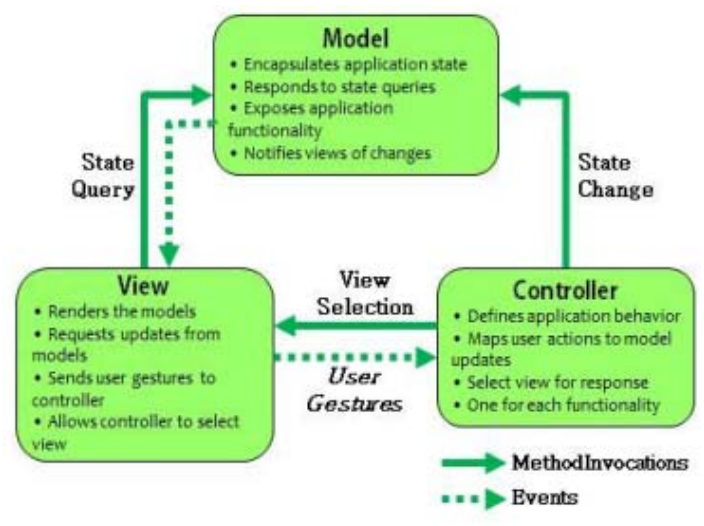

Gambar 3 Arsitektur MVC [9]

Model

Model mewakili database termasuk desain tabel serta relasi yang ada pada tabel tersebut. Fungsi utama dari model adalah menangani data, menerima data dari database, memasukkan data ke database, manipulasi data melalui validasi data.

View

View memberikan data model dan akan mengirimkan aktifitas dari konsistensi data display ke perubahan yang terjadi. Dengan mengelompokkan semua display serta kode presentasi pada 1 tempat, memberikan kemudahan untuk merubah display tanpa mempengaruhi data access serta business-logic.

Controller

Controller menetapkan behavior yang terjadi pada aplikasi serta memetakan behavior tersebut ke dalam aksi dari user ke model. Controller akan sangat 
berhubungan dengan view karena setiap interaksi user yang berhubungan dengan display, ditampilkan melalui controller.[9]

Google Maps merupakan aplikasi pemetaan berbasis web yang di desain oleh Google. Secara umum Google Maps menyediakan representasi peta ke dalam semua perspektif seperti street view, dan planning route untuk kepentingan pariwisata. Perspektif ini menyediakan horizontal dan vertikal gambar dari berbagai kota di seluruh dunia. Salah satu kunci utama dari fitur ini adalah Ground Overlays yang dipakai untuk menyusun gambar setiap peta. Penggunaan format file XML seperti KML (Keyhole Mark-up Languange) dipakai ke dalam peta untuk mendeskripsikan lokasi geografi dan GeoRSS dipakai untuk mengkodekan lokasi ke dalam bagian peta. Zoom bar selalu diperbarui oleh viewer yang mengizinkan fitur zoom [10].

API (Application Programming Interface) berfungsi untuk mengkomunikasikan dua atau lebih sistem. API memiliki koleksi tools, protocols, routines, yang bertujuan membangun software dan membantu programmer lebih mudah dalam pengkodean. Google Maps API diperkenalkan pada tahun 2005 agar Google Maps dapat ditanamkan pada website. Google Maps API memiliki berbagai macam fitur seperti zooming, panning, scalling, dan lain-lain [11]. Google Maps API berbentuk library Javascript untuk mengakses informasi geografis pada Google Maps, sehingga web programmer dapat membuat website-nya sendiri yang memiliki fitur SIG dengan bantuan dari Google Maps. Web programmer cukup berkonsentrasi pada data-data utamanya, sementara data geografis dan peta diserahkan ke Google Maps sehingga dapat dilakukan penghematan biaya dan waktu untuk membangun SIG. Desain arsitektur Google Maps API dapat dilihat pada Gambar 4.[12]

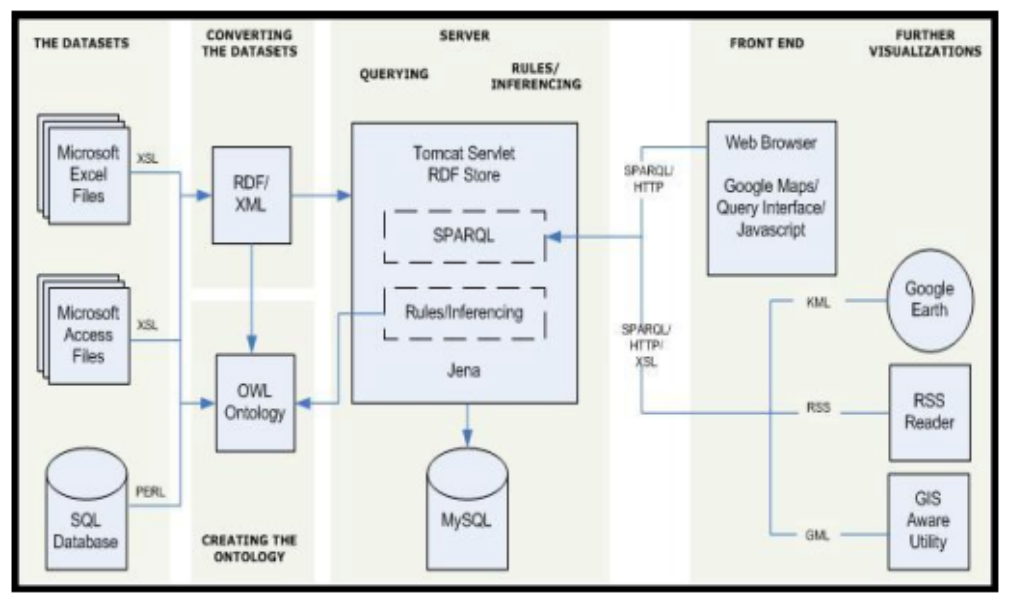

Gambar 4 Desain Arsitektur Google Maps API [12]

\section{Metode Penelitian}

Perancangan Pemetaan PHBS dilakukan dalam beberapa tahap antara lain analisis kebutuhan serta pengambilan data, perancangan aplikasi, pembuatan 
AITI: Jurnal Teknologi Informasi

aplikasi dan pengujian serta analisis hasil pengujian. Tahap analisis kebutuhan serta pengambilan data merupakan tahapan dalam identifikasi permasalahan yang terkait dengan dengan Pemetaan PHBS. Dilakukan wawancara dengan KaBid Promosi Kesehatan DKK Salatiga dan admin Promosi Kesehatan DKK Salatiga, guna mendapatkan data serta menentukan system requirement pada pembuatan Pemetaan PHBS.

Data yang didapatkan berupa tabel perhitungan dalam penentuan strata PHBS baik di tingkat keluarga maupun kelurahan. Data lain yang didapatkan berupa data-data PHBS rumah tangga masyarakat Kota Salatiga dari tahun 2012 sampai 2015 yang telah di-input-kan secara manual oleh admin Promosi Kesehatan. Data tersebut kemudian diolah pada tahap pengujian pada sistem yang dibangun Tahap perancangan aplikasi merupakan tahapan perancangan website Pemetaan PHBS mulai dari database hingga user interface (UI). Unified Modelling Languange (UML) digunakan untuk merancang sistem yang terdiri dari usecase diagram, sequence diagram, activity diagram, dan class diagram. Tahapan perancangan yang lain yaitu perancangan user interface serta drawing polygon pada Google Maps API.

Tahap berikutnya yaitu pembuatan aplikasi. Model Prototype digunakan sebagai metode pengembangan sistem. Model Prototype merupakan metode yang menyajikan gambaran lengkap tentang sistemnya, user dapat melihat pemodelan sistem dari sisi tampilan maupun teknik prosedural yang akan dibangun [13]. Gambar mengenai model prototype dapat dilihat pada Gambar 5.

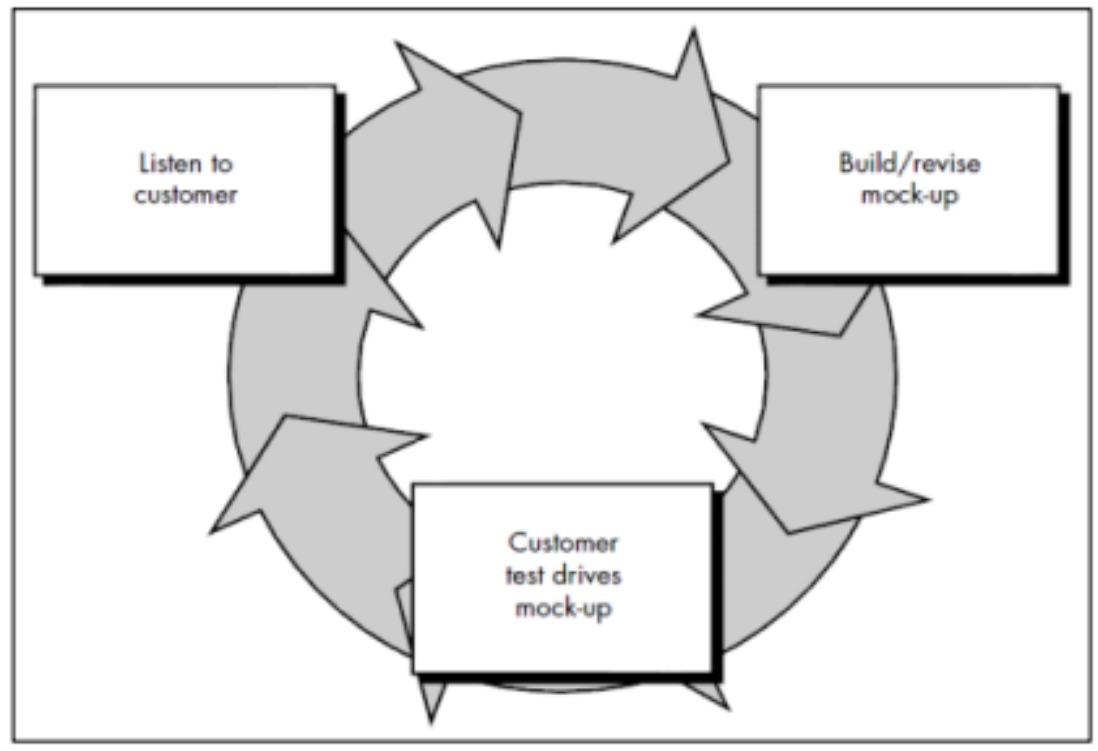

Gambar 5 Bagan Prototype Model [14]

Tahap-tahap dalam model prototype adalah : (1) Listen To Costumer, (2) Build, (3) Customer Test. Pada tahap pertama didapatkan kebutuhan sistem yaitu aplikasi mengolah data serta melakukan perhitungan strata secara otomatis yang 
kemudian hasil dari perhitungan data tersebut terintegrasi dengan peta secara visual. Kebutuhan tersebut didapatkan melalui tahap analisis kebutuhan dan pengumpulan data dari tahapan penelitian yang dilakukan. Tahap Build merupakan tahapan perancangan serta pembuatan aplikasi. Perancangan aplikasi dibuat menggunakan UML (Unified Modelling Languange) yang meliputi Use Case Diagram, Activity Diagram, dan Sequence Diagram. Use Case Diagram menggambarkan interaksi yang terjadi antara actor dan sistem. Use Case Diagram dari sistem ini dapat dilihat pada Gambar 6.

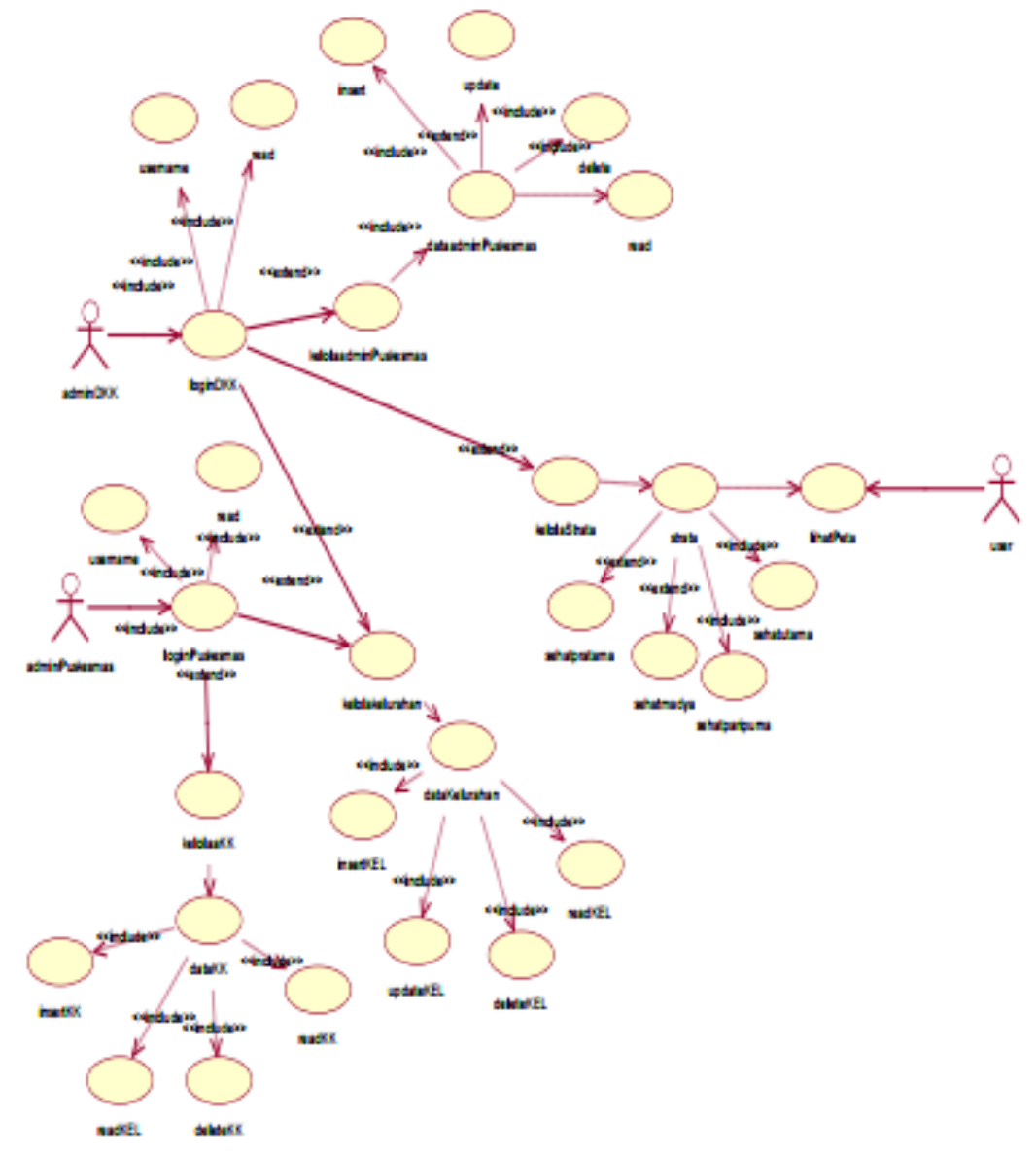

Gambar 6 Use Case Diagram

Gambar 6 menunjukkan bahwa terdapat tiga aktor dalam sistem yaitu admin DKK, admin Puskesmas serta user. User yang dimaksud adalah masyarakat Kota Salatiga. Ketiga aktor memiliki interaksi yang berbeda - beda dengan sistem. Admin DKK dapat melakukan proses penentuan strata PHBS yang masuk pada interaksi mengelola strata. Interaksi lainnya DKK adalah mengelola namun hak aksesnya terbatas. Admin DKK hanya diijinkan melihat data wilayah karena fungsi penambahan data, hapus data, serta update data dilakukan oleh admin Puskesmas. Admin DKK dapat melakukan proses mengelola data admin Puskesmas yang terdiri dari melihat data admin membuat admin baru, update admin, dan hapus data admin. 
AITI: Jurnal Teknologi Informasi

Volume 16 No. 1 Februari 2019, 1-17

Admin Puskesmas memiliki interaksi mengelola data KK serta data wilayah dan User hanya memiliki interaksi melihat peta.

Class diagram menggambarkan interaksi antar class serta atribut - atribut yang melekat pada class tersebut. Class diagram dilihat pada Gambar 7.

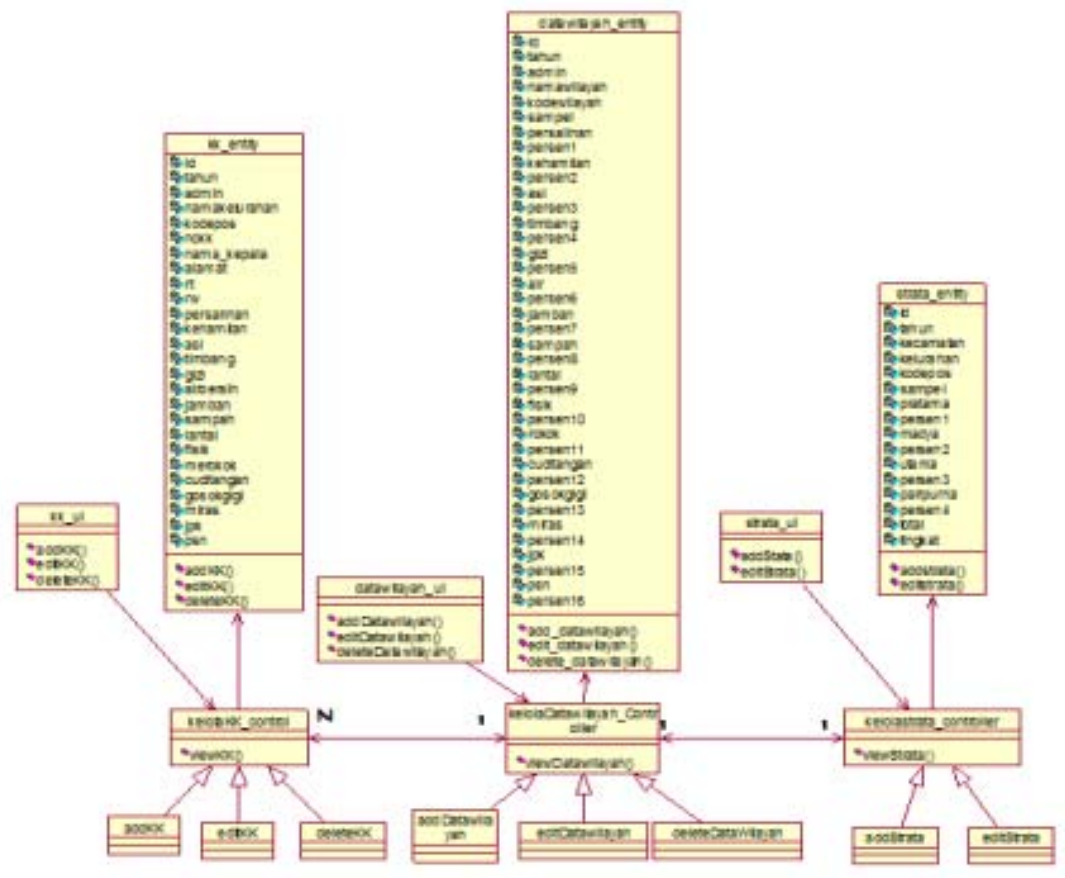

Gambar 7 Class Diagram

Selain Use Case Diagram dan Class Diagram, terdapat juga Activty Diagram. Alur aktifitas aktor dari awal hingga berakhirnya suatu use case digambarkan oleh Activity Diagram. Activity Diagram yang dibahas merupakan aktifitas dari admin DKK dalam menentukan strata. Activity Diagram dapat dilihat pada Gambar 8.

Gambar 8 menggambarkan bahwa admin DKK menerima data dari admin Puskesmas berupa strata KK per kelurahan. Admin DKK melakukan pemyortiran data sesuai kelurahan masing - masing setelah data KK diterima oleh admin DKK. Proses perhitungan dilakukan setelah data KK sudah lengkap dengan rumus strata KK Utama + Strata KK Paripurna dibagi jumlah sampel. Hasil dari perhitungan tersebut mendapatkan strata PHBS Rumah Tangga per kelurahan yang kemudian dicetak sebagai rekap hasil strata tahunan PHBS Rumah Tangga per kelurahan Kota Salatiga. 


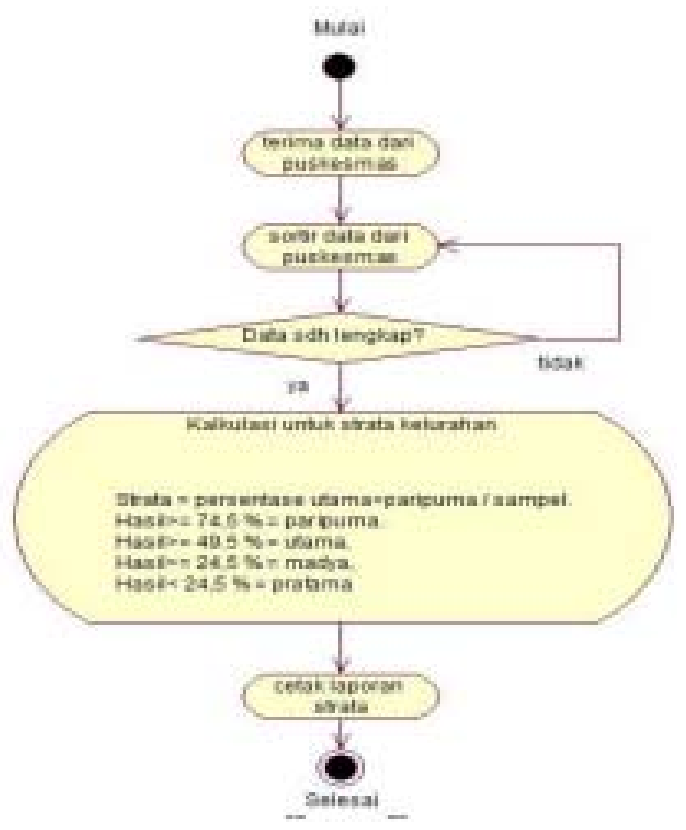

Gambar 8 Activity Diagram Admin DKK

Sequence Diagram memperlihatkan event-event yang berurutan sepanjang sepanjang berjalannya waktu. Sequence Diagram yang dibahas adalah aktifitas admin DKK dalam input strata serta menampilkan strata ke peta. Gambaran Sequence Diagram ditunjukkan pada Gambar 9.

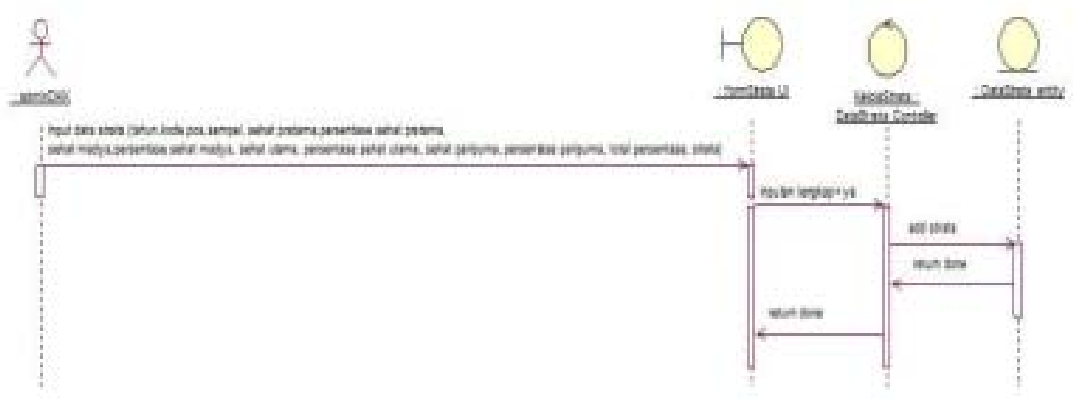

Gambar 9 Sequence Diagram

Selain perancangan sistem, perancangan user interface serta drawing polygon juga dilakukan agar pembuatan website Pemetan PHBS lebih mudah dan terarah. Terdapat tiga user interface yang dirancang yaitu, dashboard admin DKK, dashboard admin Puskemas serta beranda untuk menampilkan peta. Perancangan dashboard admin DKK dapat dilihat pada Gambar 10.

Gambar 10 menggambarkan bahwa terdapat 3 menu dalam dashboard admin DKK yaitu data wilayah, data strata dan tambah admin Puskesmas. Sesuai use case bahwa hak akses admin DKK terhadap menu data wilayah adalah read only. Perancangan dashboard admin Puskesmas dapat dilihat pada Gambar 11. 


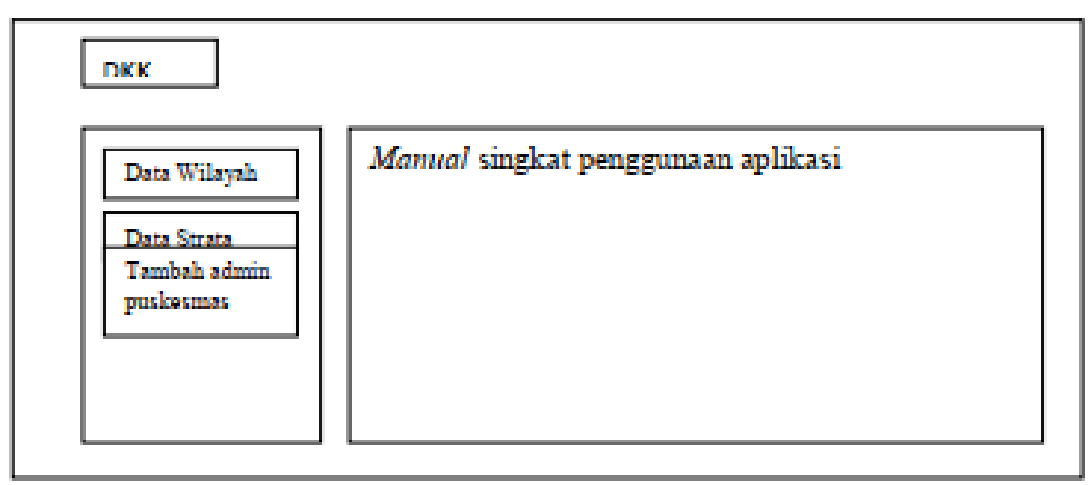

Gambar 10 Dashboard admin DKK

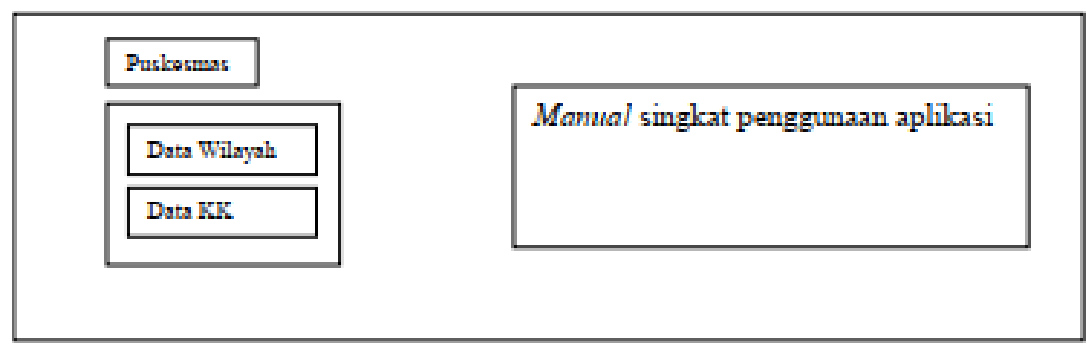

Gambar 11 Dashboard admin Puskesmas

Gambar 11 merupakan rancangan dashboard admin Puskesmas. Desain dan tampilan tidak jauh berbeda dengan admin DKK. Terdapat 2 menu pada dashboard ini antara lain data wilayah dan data KK. Hak akses pada menu data wilayah antara lain create, read, update dan delete. Perancangan beranda dapat dilihat pada Gambar 12.

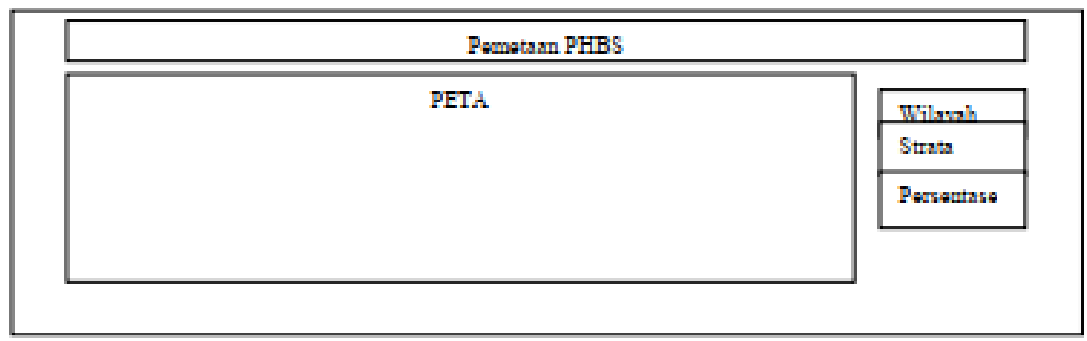

Gambar 12 Beranda

Gambar 12 merupakan rancangan user interface beranda. Menu beranda ini dapat diakses oleh user atau masyarakat Kota Salatiga. Adapun menu dari user interface ini antara lain peta, nama wilayah, strata serta persentase wilayah. Tahap selanjutnya setelah dilakukan perancangan sistem serta user interface adalah proses pembuatan aplikasi. Pembuatan website menggunakan framework Codeigniter serta penggunaan Google Maps API sebagai sumber pemrograman peta. Tahap selanjutnya adalah prototype testing. Black box testing digunakan untuk melihat fungsionalitas dari aplikasi yang dibuat. Hasil akhir di uji coba oleh admin DKK serta admin Puskesmas. 
Gambar 12 merupakan arsitektur website Pemetaan PHBS DKK Salatiga. Terdapat tiga user interface (UI) yaitu Data KK, Data Kelurahan serta Data Strata. Sesuai konsep MVC, ketiga user interface diakses melalui masing - masing controller. UI KK diakses melalui controller Kelola KK, UI Data Kelurahan diakses melalui controller Kelola Data Kelurahan, dan UI Strata diakses melalui controller Kelola Strata. Proses simpan ke database dilakukan pada masing - masing model yaitu model Data KK, Data Kelurahan serta Data Strata.

\section{Hasil dan Pembahasan}

Hasil dari penelitian ini merupakan aplikasi dalam bentuk website yang diimplementasikan menggunakan browser. Seperti yang telah dijelaskan sebelumnya mengenai CodeIgniter, aplikasi ini dibuat menggunakan metode Model, View, Controller. Sistem pemetaan ini memilik 3 controller dan 3 model utama yang memiliki output adalah pemetaan strata PHBS per kelurahan Kota Salatiga yang dimana strata PHBS dibagi menjadi beberapa kategori yang diatur sesuai rumus strata. Merujuk pada arsitektur diagram, sistem ini menggunakan controller kk untuk mengakses user interface form KK. Controller data wilayah berfungsi untuk mengakses user interface form data wilayah dan controller strata berfungsi mengakses user interface form strata. Model utama yang digunakan ada pada model strata yang berfungsi menyimpan hasil perhitungan strata serta penetapan strata yang mendapat input dari form strata. Gambar 14 menunjukkan rumus untuk mendapatkan persentase strata PHBS tingkat kelurahan.

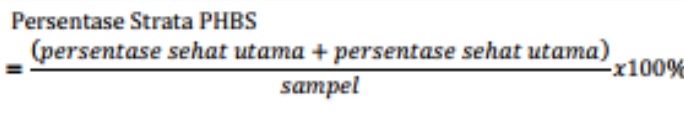

Gambar 14 Rumus persentasi strata

Hasil dari perhitungan diatas adalah strata PHBS yang kategorinya telah diatur seperti pada Gambar 15.

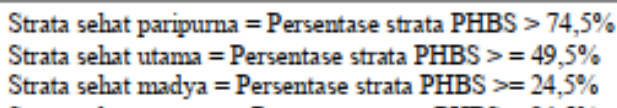

Gambar 15 Kategori strata PHBS

Tiap kategori strata PHBS, dibedakan atas 4 warna antara lain strata PHBS sehat paripurna berwarna biru, strata PHBS sehat utama berwarna hijau, strata PHBS sehat madya berwarna kuning dan strata PHBS pratama berwarna merah. Semua proses perhitungan persentase strata maupun penentuan strata PHBS dilakukan secara otomatis oleh sistem. Kode Program 1 merupakan proses kalkulasi serta penentuan strata PHBS. 
AITI: Jurnal Teknologi Informasi

Kode Program 1 Proses kalkulasi strata serta persentase PHBS

1. document . hitung. pa. value $=($ parseInt $(a) /$ parseInt $($ sampel $)) * 100$;

2. document.hitung.pb.value $=($ parseInt (b)/parseInt $($ sampel $)) * 100$;

3. document. hitung. pc. value $=($ parseInt $(c) /$ parseInt $($ sampel $)) * 100$;

4. document. hitung. pd. value $=($ parseInt $(d) /$ parseInt $($ sampel $)) * 100$;

5. document.hitung.e.value $=($ (parseInt $(c) /$ parseInt $($ sampel $)) * 100)+(($ parseInt $(d) /$ parseInt (sampel) $) * 100)$;

6. if (pe>74.5) \{document.hitung.f.value="Sehat Paripurna";

7. else if $(p e>=49.5)\{$ document.hitung.f.value="Sehat Utama";

8. else if (pe>=25.5)\{ document.hitung.f.value="Sehat Madya";\}

9. else \{document.hitung.f.value="Sehat Pratama";

Baris 1 sampai 4 adalah proses perhitungan persentase tiap strata, yaitu strata sehat pratama, sehat madya, sehat utama dan sehat paripurna. Baris 5 adalah proses perhitungan total persentase dengan rumus persentase sehat utama ditambah persentase sehat paripurna dibagi jumlah sampel. Baris 6 sampai 9 merupakan proses penentuan strata PHBS Rumah Tangga. Strata sehat paripurna didapatkan apabila total persentase lebih dari $74,5 \%$. Strata sehat utama didapatkan apabila persentase lebih dari $49,5 \%$. Strata sehat madya didapatkan apabila total persentase lebih dari 24,5\%, sedangkan total persentase dibawah 24,5\%, strata PHBS yang didapatkan adalah sehat pratama. Hasil dari perhitungan tersebut kemudian disimpan ke dalam database beserta data - data pendukung yang lain seperti tahun rekap, nama kelurahan, kode pos, dan sampel. Proses penyimpanan dapat dilihat pada Kode program 2.

Kode Program 2 Controller tambah data strata

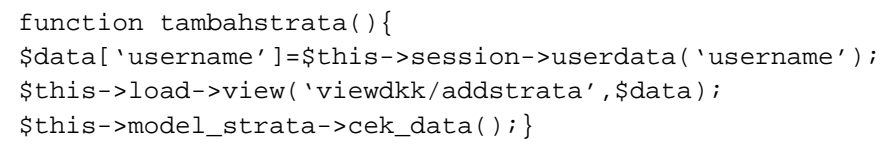

Kode program 2 merupakan fungsi untuk redirect halaman ke form tambah strata. Baris 2 merupakan fungsi untuk mengambil username session yang sedang aktif. Baris 3 merupakan fungsi redirect ke halaman form strata dan baris 4 berfungsi untuk load model yang berfungsi melakukan pengecekan data strata sebelum disimpan ke dalam database. Proses pengecekan data dapat dilihat pada Kode program 3.

Kode Program 3 Controller fungsi menampung data

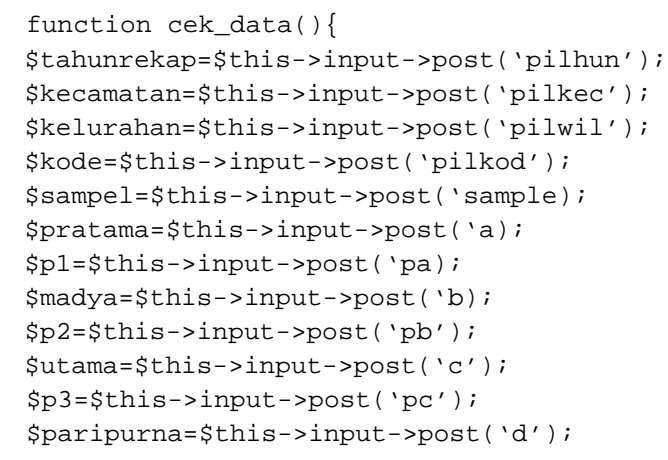


14. \$p4=\$this->input ->post ( ' $\left.p d^{\prime}\right)$;

15. \$total=\$this $->$ input $->\operatorname{post}($ ' $\mathrm{e}$ ' $)$;

16. \$strata $=\$$ this $->$ input $->\operatorname{post}\left({ }^{\prime} f^{\prime}\right)$;

Kode program 3 menjelaskan proses menampung inputan dari user saat melakukan penambahan strata menggunakan variable yang disesuaikan dengan nama attribute pada tabel. Semua input-an user ditampung dalam variable \$data yang berbentuk array seperti yang ditunjuk pada Kode Program 4.

Kode Program 4 Controller fungsi menampung data ke dalam array

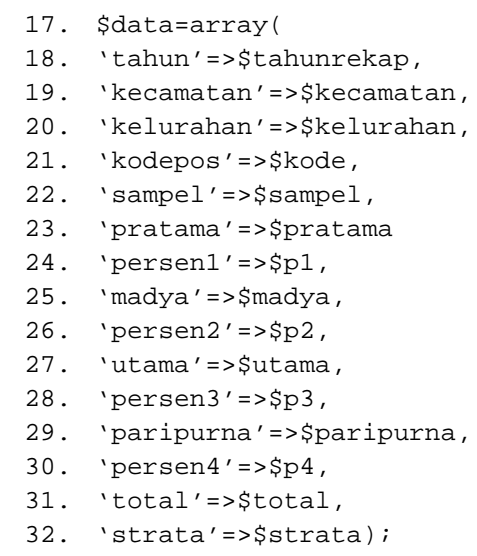

Untuk menghindari adanya duplikasi data, data kemudian di cek terlebih dahulu. Proses cek dijelaskan pada Kode Program 5.

Kode Program 5 Controller fungsi cek data ganda

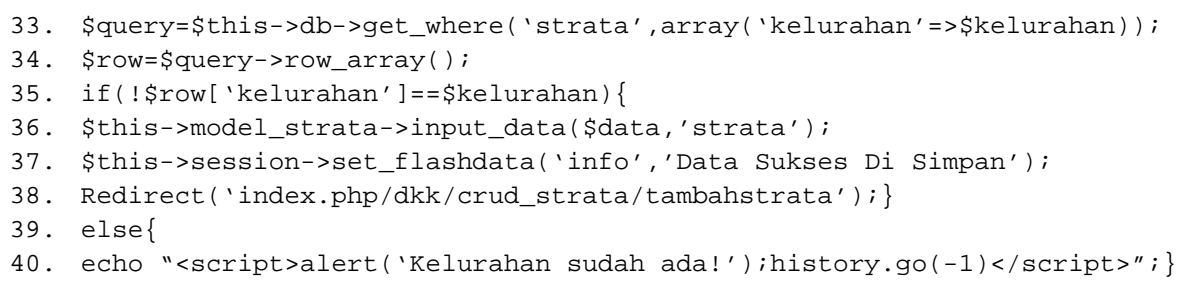

Baris 33 merupakan fungsi mengambil data atribut kelurahan sesuai inputan user. Baris 35 sampai 40 merupakan fungsi apabila tidak ada kelurahan yang sama, kemudian dilakukan input data melalui model model_strata fungsi input_data, namun apabila ada data yang sama, akan muncul pemberitahuan bahwa data sudah ada di dalam database. Fungsi input_data dijelaskan pada Kode Program 6.

Kode Program 6 Model fungsi simpan data

$$
\begin{aligned}
& \text { 41. function input_data(\$data, table })\{ \\
& \text { 42. \$this->db->insert (\$table, } \$ \text { data }) ;\}
\end{aligned}
$$

Proses insert data yang dilakukan menggunakan gaya CodeIgniter, dimana tidak perlu menuliskan kode insert yang panjang, melainkan tinggal memakai 
AITI: Jurnal Teknologi Informasi

fungsi CRUD data yang telah disediakan oleh CodeIgniter. Hal ini penulisan kode menjadi lebih efisien dan terstruktur sehingga mudah dalam pengembangan sistem. Hasil dari penambahan data strata tersebut dijadikan acuan untuk dilakukan pemetaan strata PHBS. Gambar 15 menunjukkan pemetaan strata PHBS per kelurahan Kota Salatiga.

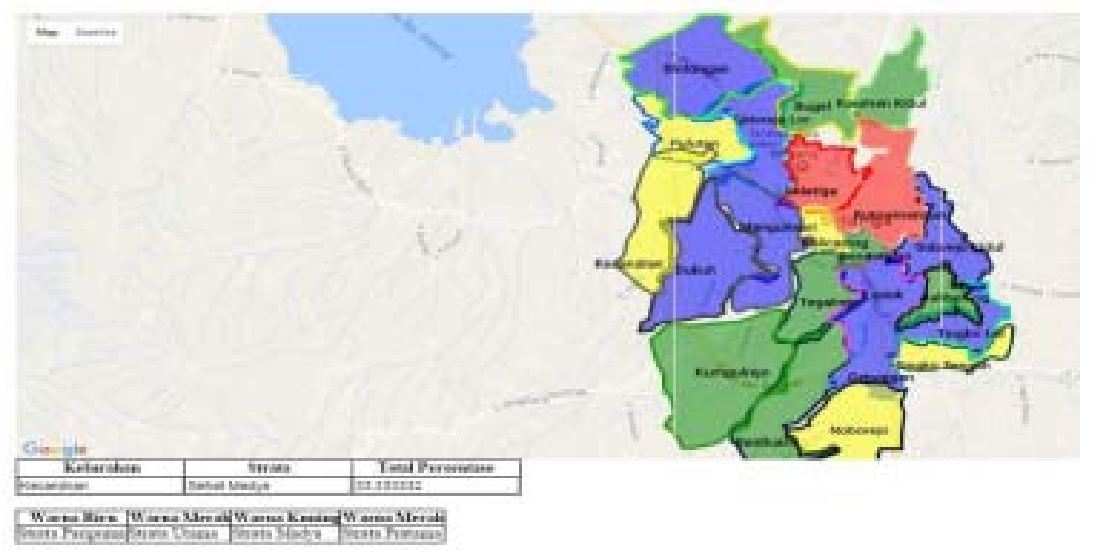

Gambar 16 Mapping PHBS per Kelurahan

Selain pemetaan, terdapat juga informasi seperti kategori strata serta total persentase strata PHBS. Warna pada tiap kecamatan akan berubah ketika strata berubah, misalnya pada kelurahan Kecandran. Kelurahan Kecandran berubah warna dari warna kuning ke warna biru seperti yang ditunjukkan pada Gambar 17.

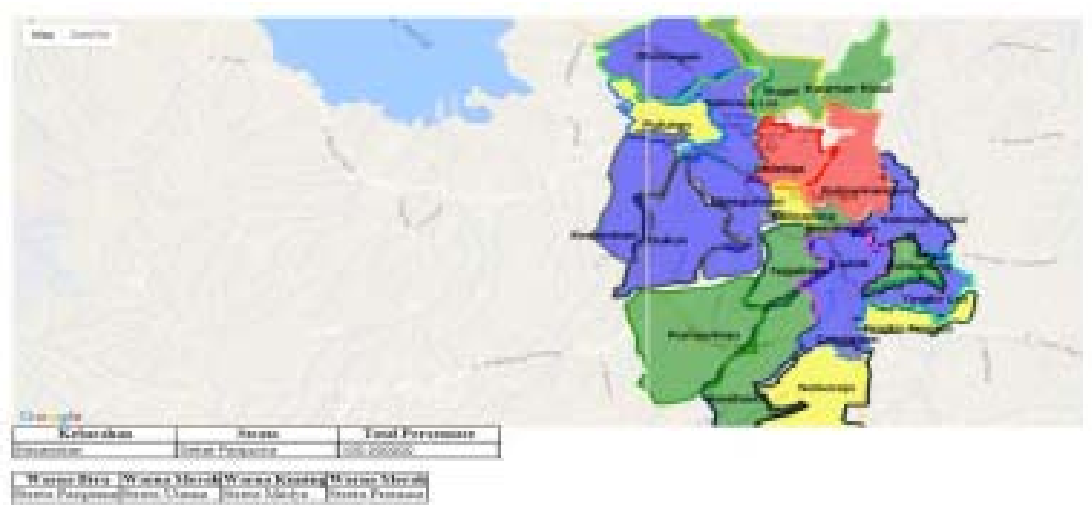

Gambar 17 Perubahan Strata Kelurahan Blotongan

Perubahan yang terjadi tidak hanya pada warna, namun juga pada info window, seperti strata dan persentase

\section{Simpulan}

Berdasarkan penelitian dilakukan dapat disimpulkan bahwa sistem informasi geografis ini dapat dibuat menggunakan framework codeigniter. Framework ini telah mendukung library Google Maps API serta fungsi CRUD sehingga proses pembuatan aplikasi menjadi lebih cepat dan efisien, karena 
penulisan kode yang panjang dapat diminimalisir. Saran pengembangan yang dapat dilakukan adalah drawing google maps yang lebih rapi dan presisi serta tampilan peta yang lebih responsif sehingga aplikasi dapat diakses secara multiplatform baik melalui perangkat mobile maupun perangkat dekstop.

\section{Daftar Pustaka}

[1] Gani,H,A,2013,'Perilaku Hidup Bersih Sehat Pada Masyarakat Using Di Kabupaten Banyuwangi ', Jurnal IKESMA, 9(2),147-158.

[2] Prita,E,P, 2015, 'Perilaku Hidup Bersih Sehat Pada Tatanan Rumah Tangga Masyarakat Using, (Online), (Repository Universitas Jember. http: //repository.unej.ac.id/bitstream/handle/123456789/73501/112110101018Pri ta\%20Eka\%20Pratiwi-1-78.pdf? sequence=1,diakses tanggal 2 Februari 2017)

[3] Raharjo, Agus, 2010, PHBS Umum, (Online), (http://www.slideshare.net/agusraharjo/phbs-umum, diakses 20 April 2017)

[4] Dinas Kesehatan Kota Salatiga, 2012, Buku Putih Sanitasi,(Online), (http://ppsp.nawasis.info/dokumen/perencanaan/sanitasi/pokja/bp/sanitasi/sa latiga/BAB\%203.doc, diakses tanggal 2 Februari 2017).

[5] Setiabudi, D, H, Rostianingsih, S \& LadyJoanna, T, J, 2010,' Sistem Informasi Geografis Dengan Fitur Peta dan Rute Perjalanan Studi Kasus Kota Malang. [Online], (http://repository.petra.ac.id/16943/1/Publikasi1_85009_1401.pdf, diakses tanggal 2 Februari 2017).

[6] Ariwibowo, E, 2013, 'Sistem Informasi Geografis Pemetaan Potensi SMA/SMK Berbasis Web', Jurnal Sarjana Teknik Informatika,1(1) 712-720.

[7] Hamidi, 2012, 'Sistem Informasi Geografis Berbasis Web Penyebaran Dana Bantuan Operasional Sekolah', Jurnal Masyarakat Informatika . 2(3).

[8] Pandie, S, 2009, 'Sistem Informasi Geografis Untuk Perjalanan Wisata Di Kota Semarang', AITI Jurnal Informatika, 10(1), 1-9.

[9] Hustinawati, Himawan, \& A, K, Latifah , 2014, 'Perfomance Analysis Framework CodeIgniter and CakePHP in Website Creation', Intenational Journal of Computer Application, 9(4).

[10] Ramya, K, S, Reshma, S \& Venkatesan, D, R, 2015, 'Perfomance Analysis Framework CodeIgniter and CakePHP in Website Creation', Intenational Journal of Computer Application, 1(1), 28-30.

[11] Ramya, K, S, Reshma, S \& Venkatesan, D, R, 2015, 'Perfomance Analysis Framework CodeIgniter and CakePHP in Website Creation', International Journal of Computer Application , 1(1), 28-30.

[12] Munir, A, Q, 2014, 'Sistem Informasi Geografis Pemetaan Bencana Alam Menggunakan Google Maps', Jurnal Informatika, 9. 
AITI: Jurnal Teknologi Informasi

Volume 16 No. 1 Februari 2019, 1-17

[13] Anuraga, 2010, Protype Model, (Online), (http://www.slideshare.net/anuragambst1/unit2-18477505,diakses 20 April 2017)

[14] Rosmala, D, 2012,'Implementasi Aplikasi Website E-Commerce Batik Sunda Dengan Menggunakan Protokol Secure Socket Layer(SSL)', Jurnal Informatika, vol. 3(3), 58-62 